\title{
Oral health education for diabetic patients with gingivitis: Controlled before and after trial
}

\author{
Azza Fathi Ibrahim *1, Faiza Mohammed Tawfik², Ayman Khamees Matter ${ }^{3}$ \\ ${ }^{1}$ Faculity of Nursing, Nursing Education Departement, Alexandriea University, Egypt \\ ${ }^{2}$ Faculty of Nursing, Medical Surgical Nursing Department, Alexandria University, Egypt \\ ${ }^{3}$ Damanhur Health Administration, diploma in oral surgery, Alexandria University, Egypt
}

Received: June 16, 2014

DOI: $10.5430 /$ cns.v3n3p105
Accepted: May 1, 2015

Online Published: May 13, 2015

\begin{abstract}
Health education is considered the backbone of health care management predominantly with diabetic patients. In order to minimize oral health problems within this group, especially those complaining of gingivitis, nurses must be well trained in assessing the educational needs of patients regarding their oral health status. Health education about oral hygiene with pharmacological and non pharmacological agents or herbal products is considered a total management in several cases. Green tea has several benefits for oral health. It limits enzymatic changes and acts as an antimicrobial, anti-inflammatory and deodorant agent. As an herbal product, green tea is accessible, effective and safe for diabetics with gingivitis. This is a quasi-experimental study aimed at determining the effect of health education about oral care with green tea powder on diabetics' oral health knowledge, skills and gingivitis' status. The study was conducted at the three medical sections of Gamal Abd El Nasser Hospital in Alexandria, Egypt. The sample was comprised of sixty adult diabetics who were selected by convenient sampling technique according to specific inclusion criteria. Patients were randomly divided into study and control groups, thirty in each. The Oral Health Education Assessment Questionnaire (OHEAQ) was used to determine the knowledge and skills of adult diabetics regarding oral health care and associated green tea benefits. The Gingival Evaluation Interview Sheet (GEIS) was used to assess gingivitis severity and its manifestations. Results revealed that there was a statistically significant difference between the study and control groups after the first and second assessments of educational intervention with green tea powder, in relation to perceived oral health care knowledge and practices with green tea, gingival inflammation severity scores, and gingivitis manifestation scores. All of these variables were improved in favor of the study group. In conclusion, oral health education with herbs and particularly green tea is an admirable nursing intervention to improve patients' oral health literacy and oral self-care practices for adult diabetic patients with gingivitis.
\end{abstract}

Key Words: Oral health, Education, Knowledge, Practice, Green tea, Gingivitis, Diabetics

\section{INTRODUCTION}

Oral health education is directed more towards modifying attitudes and changing behavior than supplying information. It is the main preventive approach for several oral health problems such as gingivitis which is more apparent in dia- betes. Gingivitis is the inflammation of the gum that is a non-destructive periodontal disease. It is a response to bacterial biofilms that adhere to the tooth surface. It is considered as the starting point of periodontitis. Therefore, oral health awareness is a vital requirement for these patients, not only

\footnotetext{
*Correspondence: Azza Fathi Ibrahim; Email: azza_fathy2008@yahoo.com; Address: Faculity of Nursing, Nursing Education Departement, Alexandriea University, Egypt.
} 
because of the high incidence, but also for preventing gingival adverse effects such as pain, discomfort, and social and functional limitations that shape a diabetic's whole life. ${ }^{[1,2]}$

Complicated metabolic control in diabetes leads to increased chronic periodontal infection incidences, damaged blood vessels, altered inflammatory response, increased oral glucose level, and halitosis followed by dental plaque and decay in complicated cases. The clinical appearance of gingivitis (see Figure 1) is apparent in poorly controlled diabetes, which can significantly accentuate the response of gingival tissue to dental plaque. Therefore, this group of patients has an urgent need for oral health teaching since epidemiological studies have reported a high prevalence of gingivitis with them as well as inadequate oral health education. ${ }^{[2-5]}$

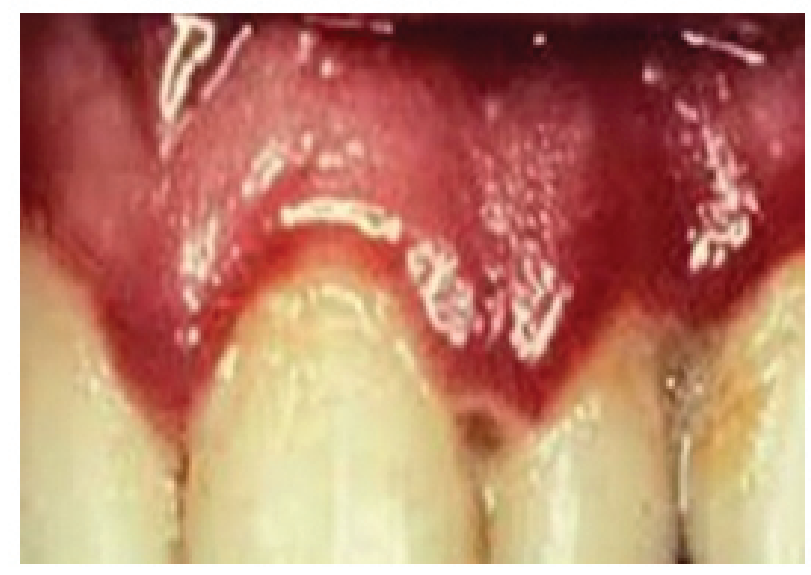

Figure 1. Gingival inflammation as a reaction of dental plaque

A 52 years old female patient has been diagnosed with type 2 diabetes since 2 years. The gingival tissue is red, edematous, bloody and friable. (Real photo was taken in the study)

Diabetes and gingivitis or periodontal diseases are clearly linked and the dual pathway of tissue destruction. Inflammation of the gingiva varies from mild or moderate to severe which is more difficult to treat. Health teaching has great benefits in gingivitis management at any level of severity. ${ }^{[4,6,7]}$

As seen in Figure 2, severe cases of gingivitis have several oral complications. Therefore, care of gingivitis among diabetic patients should be directed primarily to applying oral hygiene, thorough brushing and flossing, the use of mouth wash and gingival care. Oral health education is an effective step in dealing with oral health problems in diabetes which should be provided by health care professionals such as nurses. ${ }^{[8,9]}$ It is defined as "any learning activity which aims to improve individuals' knowledge, attitudes and skills relevant to their oral health." It is an important activity in nursing responsibilities. ${ }^{[10,11]}$ Health education is a science that draws from the biological, environmental, psychological, physical and medical sciences to promote health, prevent and manage disease or disability. Furthermore, it enables people to make informed decisions, modify and change behaviors to healthy ones. The nurse as health educator should use a scientific and systematic process of health education as an integrated part of the nursing process: assessment, planning, implementation and evaluation. ${ }^{[12,13]}$

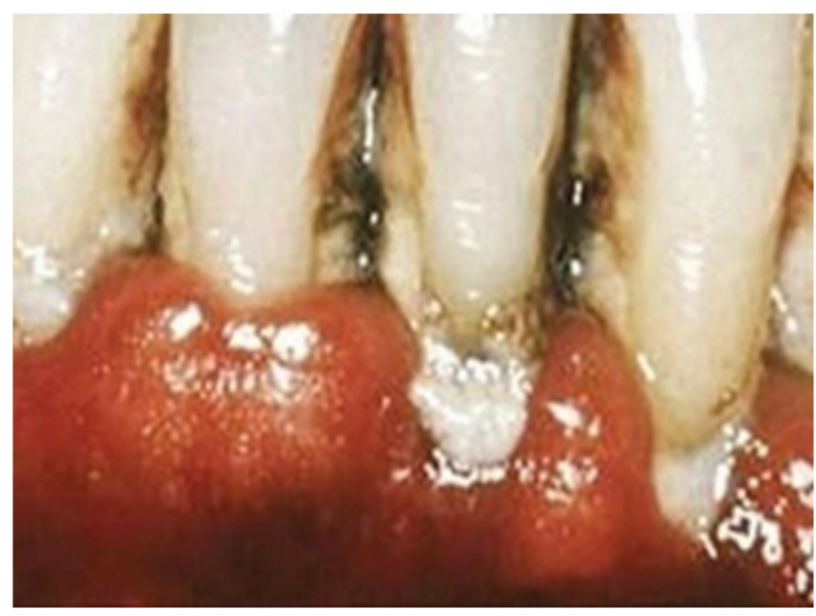

Figure 2. Severe degree of gingivitis

A 57 years old male patient has diagnosed type 2 diabetes since 8 years. The gingival tissue looks to be edematous and necrotizing. (Real photo was taken in the study)

In health education, the nurse can use several modes of management with patient complaints such as drugs, chemical solutions, diet regulation, follow up, and the use of home remedies like herbs. ${ }^{[10,14]}$ Green tea has several benefits in oral health through its immediate processing of harvested milled leaves. It limits enzymatic changes, acts as an antimicrobial and deodorant agent, helps in controlling the number of microorganisms in the mouth and reduces volatile sulfur components: VSCs as $\mathrm{H}_{2} \mathrm{~S}$ and $\mathrm{CH}_{3} \mathrm{SH}$ gases, which are the main causes of halitosis. ${ }^{[15,16]}$

Green tea and its major polyphenolic constituents, the catechins, have been comprehensively studied for their valuable health benefits, including the prevention of oral cancer, periodontal inflammation and tooth decay. Green tea has great significance in decreasing plaque which is the main triggering factor for gingival inflammation. Moreover, oral and topical application of its preparation reduces the size of lesions and the incidence of multinucleated oral mucosa cells in leukoplakia patients. Holding green tea powder in a solution in the oral cavity or chewing its leaves, results in the efficient delivering of high levels of catechins in the mouth that have been shown to combat dental plaque and bacteria 
and consequently inhibit gingival inflammation and congestion. The concentrations of $\mathrm{H}_{2} \mathrm{O}_{2}$ and catechins found in the saliva are higher when green tea is used as a powder. Thus, topical green tea powder may decrease the severity of gingival inflammation and associated manifestations by fighting plaque and oral bacteria. ${ }^{[16-19]}$

Therefore, teaching diabetic patients with gingivitis about oral care is considered an essential health concern, in particular with herbs such as green tea. It is considered a crucial step for optimum quality of oral health nursing. Accordingly, our aim is to determine the effect of health education regarding oral care using green tea powder on diabetic patients with gingivitis. To fulfill this aim, the following hypotheses were developed:

- H1: Adult diabetics who receive oral care health education exhibit higher knowledge scores about oral healthcare than those who do not receive such health education.

- H1: Adult diabetics who receive oral care health education exhibit higher skills scores in oral care than those who do not receive such health education.

- H2: Adult diabetics who receive oral care health education exhibit lower gingivitis severity index and lower manifestation severity scores than those who do not receive such health education.

\section{METHODS}

\subsection{Study design}

A quasi-experimental design was utilized to accomplish this study.

\subsection{Sample and setting}

The study was conducted at the three medical sections of Gamal Abd El Nasser Hospital in Alexandria, Egypt. A convenient sample of 60 adult diabetic male and female patients was used. The sample size was determined by an epidemiological information statistical program. The patients were randomly assigned to either Study Group A or Control Group $B$ with 30 patients in each group. Inclusion criteria was: an age range of 30 to 60 years old, alert, able to read, write and communicate, diagnosed by type 1 or 2 diabetes for at least one year, complaints of gingivitis as proven by clinical probing examination, no usage of dentures that distort the gingival layer, freedom from any other systemic associated diseases that may affect oral health status like leukemia, bleeding disorders, head and neck cancers, not being treated with chemotherapy or thrombolytic agents and finally have a willingness to participate in the study by signed written consent.

Published by Sciedu Press

\subsection{Tools}

First: An Oral Health Education Assessment Questionnaire (OHEAQ) that was developed after a thorough review of the related literature ${ }^{[8,13,20,21]}$ to determine the knowledge and skills of adult diabetics regarding oral health education with green tea powder. It was comprised of three parts: (1) Biosociodemographic data such as age, sex, education, occupation, type of diabetes, associated illness and smoking. (2) Questions to identify oral health care knowledge as perceived by diabetic adults in terms of: the complication of diabetes on oral health, awareness of oral health activities, and benefits of green tea on oral health and gingivitis. (3) Questions to assess oral health practices of adult diabetics through a rating scale which is comprised of five tasks: 1) oral assessment, 2) brushing of teeth, 3) use of mouthwash with gargling, 4) flossing, and 5) gum massaging. Each task was followed by three or four performance skills that were rated as: done (2), incomplete (1) and not done (0).

Second: A Gingival Evaluation Interview Sheet (GEIS) that was established after a thorough review of the related literature, ${ }^{[9,22,23]}$ to determine the gingivitis severity level and its manifestations. It was comprised of two parts: Part one was a Gingival Index that represented a grading of the inflammation severity by a 4 point Likert Scale. Facial and lingual surfaces at two sites on each tooth, papillae and margins, were assessed by standard dental illumination including the Distofacial papilla, Facial margin, Mesiofacial papilla, and the Entire lingual margin; scoring is $0=$ normal gingiva which means there is no change in the color or texture of any portion of the marginal or papillary gingival unit. $1=$ mild inflammation that represents a slight change in color and texture of the gingival unit. $2=$ moderate inflammation that indicates glazing, redness, edema, and/or hypertrophy of the gingival unit and slight bleeding. $3=$ severe inflammation which shows marked redness, edema and/or hypertrophy of the marginal or papillary gingival unit, spontaneous bleeding and congestion. Indications of the total score of this part: from $1 \geq 4$ represents mild gingivitis, from $5 \geq 8$ illustrates moderate gingivitis, and from $9 \geq 12$ indicate severe gingivitis. Part two was developed to assess the presence of manifestations of gingivitis. It included ten signs and symptoms, namely; bleeding, redness, swelling, tenderness, gum sores, a shiny appearance, halitosis, loose teeth, recessed gums and the presence of pus in the gingiva. The response was limited to being present $=1$ and absence $=0$. Tools were tested for content validity by seven experts in the fields of Nursing Education, Medical Surgical Nursing and Dentistry, and consequently, necessary modifications were done.

Both study tools were statistically tested for reliability. Tool one by Cronbach Alpha Coefficient Statistical Test revealed 
$\alpha=0.61$ to 0.78 of internal consistency. Tool two checked for inter rater reliability by Cohen's Kappa Coefficient Statistical Test to examine to which extent the inter-rater agreement for the items of tool 2; first part obtains $\mathrm{K}=0.53$ to 0.68 , second part obtain $\mathrm{K}=0.67$ to 0.73 , with $95 \%$ confidence interval.

\subsection{Data collection}

The authorities of Gamal Abd El Nasser Hospital approved the study protocol. A pilot was carried out on nine patients independent of the study subjects, and necessary modifications were done. Once recruited, patients were informed regarding the purpose and procedure of the study and given a written informed consent. All information was kept confidential and all data were presented as group data to preserve anonymity. Oral health education sessions were developed and carried out in four consecutive phases: assessment, planning, intervention and evaluation with Group A only.

\subsubsection{Assessment phase}

Both study tools were used with both the study and control groups on an individual basis. An oral examination was conducted using sterilized disposable gloves, a dental mirror, a periodontal probe, a tongue depressor, gauze and sponges. All were sterilized. Photographs were taken for data visualization by using a zoom camera after subjects' approval.

\subsubsection{Planning phase}

Based on a thorough review of related literature and the assessment phase, an oral health education unit was prepared including objectives, importance of oral health care especially for diabetics with gingivitis, oral health assessment and oral hygiene skills composed of brushing, gargling, flossing and gum massaging with green tea powder. A booklet with pictures as a handout was developed and used as a visual aid. The oral health education unit and handout was revised by a jury of seven experts in nursing education and the dentistry fields to ensure its content validity. They systematically examined the teaching content to determine whether it covers a representative sample of the behavior domain to be measured. Also, they identified the degree to which evidence and theory support the details of the booklet content; including pictures, knowledge and skills. According to their expert points of view, modifications were done.

A fine milled powder derived from green tea leaves was prepared to be easily dissolved in warm water and used in teeth brushing, mouth washing, gargling, flossing \& gingival massaging with wet cotton swabs. Teaching sessions with each patient individually were designed for Group A only. These included: suitable teaching methods such as discussion and demonstration, visuals, timing and place of conduction, Group B received their oral health care from hospital rou- tine, without any hospital educational interference. Oral care equipment was given to patients such as toothbrushes, cotton swabs, disposable cups, green tea powder, tissue paper and handouts. They received these materials for free. In addition, as motivational gifts, watches, tea packets and lunch breaks were provided. Researchers were trained in using dental probes and mirrors for gingival and oral examination for one month before the start of the data collection time. Different studies showed that the catechins amount in solutions with green tea powder ( $1 \mathrm{~g}$ leaves $/ 100 \mathrm{ml}$ water) ranged from $20 \mathrm{mg}$ to $130 \mathrm{mg}$. So this amount was calculated and included in the instructional session. Each mouth wash needed about a teaspoon of green tea powder.

\subsubsection{Intervention phase (with Group A only)}

Each patient in the study group was taught oral health care knowledge and skills within four months. They restated oral health knowledge and re-demonstrated oral care with green tea powder under researchers' supervision. This included oral health assessment, brushing of teeth, cleaning and massaging the gingiva and tongue with cotton swabs soaked in green tea solution, flossing, using mouthwash and gargling with dissolved green tea powder in warm water. Examples, clarifications, questions and explanations were provided while the patients demonstrated their oral care twice each session. Each patient received two teaching sessions and each session lasted about two hours. Patients were instructed to drink a cup of green tea without sugar daily and repeat the oral care with green tea powder for ten minutes twice a day for four weeks using the provided equipment and materials. Follow up was strictly enforced every two days. If a patient had been discharged, he/she was followed by telephone and asked to attend for follow up at the outpatient clinic.

\subsubsection{Evaluation phase}

Patients of both groups were assessed by the study tools three times: (1) before conduction of the health education sessions for baseline data collection as a 1st assessment, (2) after the health education sessions by 2 weeks as a 2 nd assessment, and (3) after the health education sessions by 4 weeks as a 3rd assessment. The scores of the study tools before and after the educational intervention for both groups in the three assessments were compared, and then the difference between them estimated to achieve the proposed aim.

\subsection{Data analysis}

Collected data was computerized, coded, analyzed and tabulated. Statistical Packages for the Social Sciences (SPSS) version 15.0 for Windows and Microsoft Excel Spread Sheet Package (Office 2007) were used for the results of the study. Tests for significance were used: mean and standard devi- 
ation as well as percentage, frequency, chi-square, and $P$ values.

Table 1 shows that nearly half of both groups $(50 \%, 53.3 \%)$ were in their forties age-wise, and the study convenient sample had no patients in thirties. Also, about two thirds $(70 \%$, $66.7 \%$ ) of both, were male. More than one third of them $(36.7 \%, 40 \%)$ were workers. In addition, approximately one third $(30 \%, 30 \%)$ had a high educational level. The majority of both them $(70 \%, 80 \%)$ had type II diabetes, while more than one third $(36.7 \%, 40 \%)$ of both had GIT problems associated with diabetes. There was no a statistically significant difference noticed between the study and control groups in relation to socio-demographic characteristics, level of significance $<.05$.

Table 1. Sociodemographic characteristics of both study and control groups

\begin{tabular}{|c|c|c|c|c|c|}
\hline \multirow{2}{*}{ Biosociodemographic characteristics } & \multicolumn{2}{|c|}{ Group A $(\mathbf{N}=\mathbf{3 0})$} & \multicolumn{2}{|c|}{ Group B $(\mathbf{N}=\mathbf{3 0})$} & \multirow{2}{*}{ Test of Significant $\left(\chi^{2}\right)$} \\
\hline & $\mathbf{N}$ & $\%$ & $\mathbf{N}$ & $\%$ & \\
\hline \multicolumn{6}{|l|}{ Age } \\
\hline $40 \leq 45$ & 9 & 30 & 8 & 26.7 & \multirow{4}{*}{1.23} \\
\hline $45 \leq 50$ & 6 & 20 & 8 & 26.7 & \\
\hline $50 \leq 55$ & 6 & 20 & 8 & 26.7 & \\
\hline $55 \leq 60$ & 9 & 30 & 6 & 20 & \\
\hline \multicolumn{6}{|l|}{ Sex } \\
\hline Male & 21 & 70 & 20 & 66.7 & \multirow[t]{2}{*}{0.77} \\
\hline Female & 9 & 30 & 10 & 33.3 & \\
\hline \multicolumn{6}{|l|}{ Occupation } \\
\hline Worker & 11 & 36.7 & 12 & 40 & \multirow{5}{*}{1.745} \\
\hline Employee & 6 & 20 & 5 & 16.6 & \\
\hline Farmer & 5 & 16.6 & 3 & 10 & \\
\hline Retired & 5 & 16.6 & 4 & 13.3 & \\
\hline Unemployed & 3 & 10 & 6 & 20 & \\
\hline \multicolumn{6}{|l|}{ Level of education } \\
\hline High $^{*}$ & 9 & 30 & 9 & 30 & \multirow{4}{*}{0.602} \\
\hline Moderate $^{* *}$ & 9 & 30 & 8 & 26.7 & \\
\hline Lower than Moderate ${ }^{* * *}$ & 4 & 13.3 & 5 & 16.6 & \\
\hline Low literacy (reading \& writing) & 8 & 26.7 & 8 & 26.7 & \\
\hline \multicolumn{6}{|l|}{ Diabetes type } \\
\hline Type 2 & 21 & 70 & 24 & 80 & \multirow[t]{2}{*}{0.800} \\
\hline Type 1 & 9 & 30 & 6 & 20 & \\
\hline \multicolumn{6}{|l|}{ Associated health problems } \\
\hline Gastrointestinal problems & 11 & 36.7 & 12 & 40 & \multirow{4}{*}{0.420} \\
\hline Heart disease & 8 & 26.7 & 6 & 20 & \\
\hline Renal disease & 6 & 20 & 6 & 20 & \\
\hline Respiratory diseas & 5 & 16.6 & 6 & 20 & \\
\hline \multicolumn{6}{|l|}{ Smoking } \\
\hline Yes & 18 & 60 & 21 & 70 & \multirow[t]{2}{*}{0.659} \\
\hline No & 12 & 40 & 9 & 30 & \\
\hline
\end{tabular}

Table 2 reveals an apparent improvement in the study group knowledge about perceived diabetic effects on oral health in the 2 nd and 3 rd assessments, including all items in the table: (1) inhibition of immunity, (2) provoking mouth bacteria, diabetes, proper oral hygiene tends to manage gingivitis. The
(3) enhancing gingival inflammation and aggravating tooth decay, (4) diabetes may be controlled by regular health education, (5) treating diabetes may manage gingivitis, and (6) in 
Study Group percents were $(83.3 \%, 90 \%, 83.3 \%, 90 \%, 90 \%$ difference was found between the study and control groups and $83.3 \%$ ) compared with the Control Group $\left(53.3 \%, 3.3 \%\right.$, in relation to the above mentioned variables $\chi^{2}=19.3,23.4$, $13.3 \%, 36.7 \%, 33.3 \%$ and 6.6\%). A significant statistical 27.3, 21.4, 22.9, and 23.4 respectively.

Table 2. Knowledge about the effects of diabetes on oral health as perceived by the study and control groups in the 1st, 2nd, and 3rd assessments before and after health education intervention

\begin{tabular}{|c|c|c|c|c|c|c|c|c|c|c|c|c|c|c|c|}
\hline \multirow{3}{*}{ Perceived effects of diabetes } & \multicolumn{6}{|c|}{ Group A } & \multicolumn{6}{|c|}{ Group B } & \multicolumn{3}{|c|}{$\chi^{2}$} \\
\hline & \multicolumn{2}{|c|}{ 1st } & \multicolumn{2}{|c|}{ 2nd } & \multicolumn{2}{|c|}{ 3rd } & \multicolumn{2}{|c|}{ 1st } & \multicolumn{2}{|c|}{ 2nd } & \multicolumn{2}{|c|}{ 3rd } & \multirow{2}{*}{ 1st } & \multirow{2}{*}{ 2nd } & \multirow{2}{*}{ 3rd } \\
\hline & $\mathbf{N}$ & $\%$ & $\mathbf{N}$ & $\%$ & $\mathbf{N}$ & $\%$ & $\mathbf{N}$ & $\%$ & $\mathbf{N}$ & $\%$ & $\mathbf{N}$ & $\%$ & & & \\
\hline Decreased body immunity & 11 & 36.7 & 20 & 66.7 & 25 & 83.3 & 12 & 40 & 13 & 43.3 & 16 & 53.3 & 1.6 & $6.7^{*}$ & $19.3^{* *}$ \\
\hline Leads to mouth bacteria & 2 & 6.6 & 15 & 50 & 27 & 90 & 1 & 3.3 & 10 & 33.3 & 1 & 3.3 & 1.4 & $9.7^{*}$ & $23.4^{* *}$ \\
\hline Leads to gingivitis \& tooth decay & 3 & 10 & 13 & 43.3 & 26 & 83.3 & 2 & 6.7 & 2 & 6.7 & 4 & 13.3 & $7.8^{*}$ & $8.9^{*}$ & $27.3^{* *}$ \\
\hline $\begin{array}{l}\text { Requires regular oral health } \\
\text { education }\end{array}$ & 8 & 26.7 & 17 & 56.7 & 27 & 90 & 9 & 30 & 10 & 33.3 & 11 & 36.7 & 1.7 & $7.3^{*}$ & $21.4^{* *}$ \\
\hline $\begin{array}{l}\text { Control of diabetes leads to } \\
\text { management of gingivitis }\end{array}$ & 2 & 6.6 & 19 & 63.3 & 27 & 90 & 12 & 40 & 9 & 30 & 10 & 33.3 & 1.5 & $9.3^{*}$ & $22.9^{* *}$ \\
\hline $\begin{array}{l}\text { Proper oral hygiene manages } \\
\text { gingivitis }\end{array}$ & 2 & 6.6 & 15 & 50 & 26 & 83.3 & 2 & 10 & 13 & 43.3 & 2 & 6.6 & 1.4 & $9.7^{*}$ & $23.4^{* *}$ \\
\hline
\end{tabular}

${ }^{*} p \leq .05 ;{ }^{* *} p \leq .01 ;{ }^{* * *} p \leq .001 ; \mathrm{DF}=$ Degree of freedom $=1$.

As observed in Table 3, there was a statistically significant difference between the study and control groups $(p \leq .01)$ in the 2 nd and $3 r d$ assessments in relation to awareness about all of oral health care activities: Frequency of oral hygiene $\left(\chi^{2}=22.36,33.67\right)$, Teeth cleansing methods $\left(\chi^{2}=11.99\right.$, 23.40), Frequency of dental visits $\left(\chi^{2}=16.22,24.25\right)$, Assessment of oral health $\left(\chi^{2}=19.20,10.94\right)$, Flossing of gingiva $\left(\chi^{2}=7.26,14.30\right)$, Massaging of gums $\left(\chi^{2}=14.73\right.$, 13.33), Using green tea with gingivitis $\left(\chi^{2}=19.20,22.09\right)$. It is clear that the Study Group had a noticeable improvement in perceiving all mentioned oral health activities in the third assessment as compared with the control group: Performing oral hygiene twice daily (53.3\% vs. 6.7\%), Brushing with toothpaste ( $83.3 \%$ vs. 30\%), Dental visits once/month (50\% vs. $10 \%)$, Assessment of oral health $(86.7 \%$ vs. $23.3 \%)$, Flossing of gingiva (100\% vs. 23.3\%), Massage of gums (83.3\% vs. $16.7 \%)$, Using green tea with gingivitis $(100 \%$ vs. $10 \%)$.

In Table 4, there was a statistically significant difference between the study and control groups after the 2nd and 3rd assessments in relation to oral health care practices: oral health assessment $\left(\chi^{2}=15.06,16.75\right)$, teeth brushing $\left(\chi^{2}\right.$ $=13.187,23.409)$, flossing $\left(\chi^{2}=11.88,15.04\right)$, and gum massaging $\left(\chi^{2}=22.49,34.73\right)$. Improvement was apparently observed for mouth wash in the 3 rd assessment $\left(\chi^{2}=\right.$ 19.04). Generally, all oral care practices of the study group improved in the 2 nd and $3 \mathrm{rd}$ assessment rather than in the control group.

Table 5 indicates an obvious improvement in gingivitis inflammation severity in the Distofacial papilla and Facial margin for the study group in the 2nd and 3rd assessments, as compared with the control group: regarding the Distofacial papilla inflammation, the majority $(30 \%, 40 \%$ and $40 \%, 26.7 \%$ ) of the study and control groups in 1st assessment, respectively, had severe and moderate inflammation, as compared to $33.3 \%, 50 \%$ in the study group and $6.7 \%$, $26.7 \%$ of the control group who had mild inflammation and a normal condition of Distofacial papilla in the 2nd and 3rd assessments. There was a significant difference between the two groups in the 2nd and 3rd assessments regarding the degree of inflammation severity in the Distofacial papilla $\left(\chi^{2}\right.$ $=17.45,18.30)$ and the Facial margin $\left(\chi^{2}=28.67,24.93\right)$. With regards to the Mesiofacial papilla, and the Entire lingual margin, the significant difference was apparent after the 3rd assessment only ( $\left.\chi^{2}=12.13,25.73\right)$.

According to the data in Table 6, there was a statistically significant difference between the study and control groups $(p \leq$ $.01)$ in the 2nd and 3rd assessments, in relation to the following manifestations: gingival redness $\left(\chi^{2}=6.789,11.315\right)$, gingival tenderness $\left(\chi^{2}=32.308,37.297\right)$, gingival shininess $\left(\chi^{2}=30.00,32.308\right)$, halitosis $\left(\chi^{2}=9.317,25.714\right)$, and pus in gingiva $\left(\chi^{2}=6.789,25.714\right)$. Nearly, all these manifestations disappeared with the study group. For example, before using green tea powder in the 1st assessment pus in the gingiva was present in $(86.7 \%, 60 \%)$ of the study and control groups but in the 2nd assessment, the proportions became $(40 \%, 73.3 \%)$, and then in the $3 \mathrm{rd}$ assessments, the percentages reached $(0 \%, 40 \%)$ among both groups.

In relation to Gum bleeding, Swollen gingiva, Gingival sores and Receding gums, there was a statistically significant dif- 
ference between the study and control groups $(p \leq .05)$ after significant difference between the study and control groups the 3 rd assessment $\left(\chi^{2}=15.58,4.32,11.88\right.$, and 5.192). All $(p \leq .05)$ in the 2 nd and 3rd assessments, also in favor of these features decreased within the study group rather than study group.

the control group. For Loose teeth, there was a statistical

Table 3. Knowledge about oral health care activities among the study and control groups in the 1st, 2nd, and 3rd assessments, before and after the health education intervention

\begin{tabular}{|c|c|c|c|c|c|c|c|c|c|c|c|c|}
\hline \multirow{3}{*}{$\begin{array}{l}\text { Awareness of oral health } \\
\text { care activities }\end{array}$} & \multicolumn{4}{|c|}{ 1st assessment } & \multicolumn{4}{|c|}{ 2nd assessment } & \multicolumn{4}{|c|}{ 3rd assessment } \\
\hline & \multicolumn{2}{|c|}{ Group A } & \multicolumn{2}{|c|}{ Group B } & \multicolumn{2}{|c|}{ Group A } & \multicolumn{2}{|c|}{ Group B } & \multicolumn{2}{|c|}{ Group A } & \multicolumn{2}{|c|}{ Group B } \\
\hline & $\mathbf{N}$ & $\%$ & $\mathbf{N}$ & $\%$ & $\mathbf{N}$ & $\%$ & $\mathbf{N}$ & $\%$ & $\mathbf{N}$ & $\%$ & $\mathbf{N}$ & $\%$ \\
\hline \multicolumn{13}{|l|}{ Frequency of oral hygiene } \\
\hline Never & 15 & 50 & 12 & 40 & 2 & 6.7 & 10 & 33.3 & - & - & 9 & 30 \\
\hline Once/weekly & 3 & 10 & 5 & 16.7 & 5 & 16.7 & 6 & 20 & 1 & 3.3 & 8 & 26.7 \\
\hline Once/daily & 5 & 16.6 & 8 & 26.6 & 2 & 6.7 & 10 & 33.3 & 3 & 10 & 9 & 30 \\
\hline Twice/daily & 2 & 6.7 & 2 & 6.7 & 12 & 40 & 2 & 6.7 & 16 & 53.3 & 2 & 6.7 \\
\hline Three times / daily & 5 & 16.6 & 3 & 10 & 9 & 30 & 2 & 6.7 & 10 & 33.3 & 2 & 6.7 \\
\hline$\overline{\mathrm{X}} \pm \mathrm{SD}$ & \multicolumn{2}{|c|}{$6 \pm 5.2$} & \multicolumn{2}{|c|}{$6 \pm 4.06$} & \multicolumn{2}{|c|}{$6 \pm 4.42$} & \multicolumn{2}{|c|}{$6 \pm 4.0$} & \multicolumn{2}{|c|}{$6 \pm 6.82$} & \multicolumn{2}{|c|}{$6 \pm 3.67$} \\
\hline$\chi^{2}$ & \multicolumn{4}{|c|}{2.26} & \multicolumn{4}{|c|}{$22.36^{* *}$} & \multicolumn{4}{|c|}{$33.67^{* *}$} \\
\hline \multicolumn{13}{|l|}{ Teeth cleansing methods } \\
\hline Rinsing with soap \& water & 10 & 33.3 & 9 & 30 & 2 & 6.7 & 6 & 20 & 2 & 6.7 & 4 & 13.3 \\
\hline Rinsing with salt \& water & 3 & 10 & 6 & 20 & - & - & 4 & 13.3 & - & - & 8 & 26.7 \\
\hline Swak & 2 & 6.7 & 1 & 3.3 & 4 & 13.3 & 5 & 16.7 & 3 & 10 & 2 & 6.7 \\
\hline None & 10 & 33.3 & 6 & 20 & 2 & 6.7 & 5 & 16.7 & - & - & 7 & 23.3 \\
\hline$\overline{\mathrm{X}} \pm \mathrm{SD}$ & \multicolumn{2}{|c|}{$6 \pm 3.81$} & \multicolumn{2}{|c|}{$6 \pm 3.08$} & \multicolumn{2}{|c|}{$6 \pm 9.06$} & \multicolumn{2}{|c|}{$6 \pm 2.35$} & \multicolumn{2}{|c|}{$6 \pm 10.7$} & & \\
\hline$\chi^{2}$ & & & & & & & $99^{* *}$ & & & & & \\
\hline Frequency of dental visits & & & & & & & & & & & & \\
\hline Once/week & - & - & 3 & 10 & 10 & 33.3 & 8 & 26.7 & 12 & 40 & 6 & 20 \\
\hline Once/month & 10 & 33.3 & 6 & 20 & 10 & 33.3 & - & - & 15 & 50 & 3 & 10 \\
\hline Once $/ 3$ months & 9 & 30 & 7 & 23.3 & 4 & 13.3 & 4 & 13.3 & 2 & 6.7 & 6 & 20 \\
\hline Never & 11 & 36.7 & 14 & 46.7 & 6 & 20 & 18 & 60 & 1 & 3.3 & 15 & 50 \\
\hline$\overline{\mathrm{X}} \pm \mathrm{SD}$ & & & & & & & & & & & & \\
\hline Assessment of oral health & 5 & 16.7 & 3 & 10 & 27 & 90 & 3 & 10 & 26 & 86.7 & 7 & 23.3 \\
\hline$\chi^{2}$ & & & & & & & $20^{* *}$ & & & & & \\
\hline Flossing of gingiva & 10 & 33.3 & 6 & 20 & 23 & 76.7 & 8 & 26.7 & 30 & 100 & 7 & 23.3 \\
\hline$\chi^{2}$ & & & & & & & $6^{* *}$ & & & & & \\
\hline Massaging of gums & - & - & - & - & 20 & 66.7 & 2 & 6.7 & 25 & 83.3 & 5 & 16.7 \\
\hline$\chi^{2}$ & & & & & & & $73^{* *}$ & & & & & \\
\hline $\begin{array}{l}\text { Using green tea with } \\
\text { gingivitis }\end{array}$ & 2 & 6.7 & - & - & 27 & 90 & 3 & 10 & 30 & 100 & 3 & 10 \\
\hline$\chi^{2}$ & & & & & & & $20^{* *}$ & & & & & \\
\hline
\end{tabular}

$" p \leq .05 ;{ }^{* *} p \leq .01 ;{ }^{* * *} p \leq .001$

\section{Discussion}

Nurses are often the professionals for assisting and offering skilled care when needed, advocating, teaching, guiding people about health decision-making, standing by at critical moments, helping in disease understanding and reassuring when confronted with patient doubts or fear. Nurses are the key ones to provide health education. The nurse as a health Published by Sciedu Press educator should be aware of updating knowledge and the educational, communicational, and social process of health education. Moreover, they should be competent in using educational strategies in establishing teaching interventions which help in addressing the needs of patients, particularly those with a complaint in a vital body part such as the mouth. Oral health education involves several aspects of disease management; medications or chemicals and herbal uses. ${ }^{[13,24,25]}$ 
Table 4. Oral health care practices among the study and control groups in the 1st, 2nd, and 3rd assessments, before and after the health education intervention

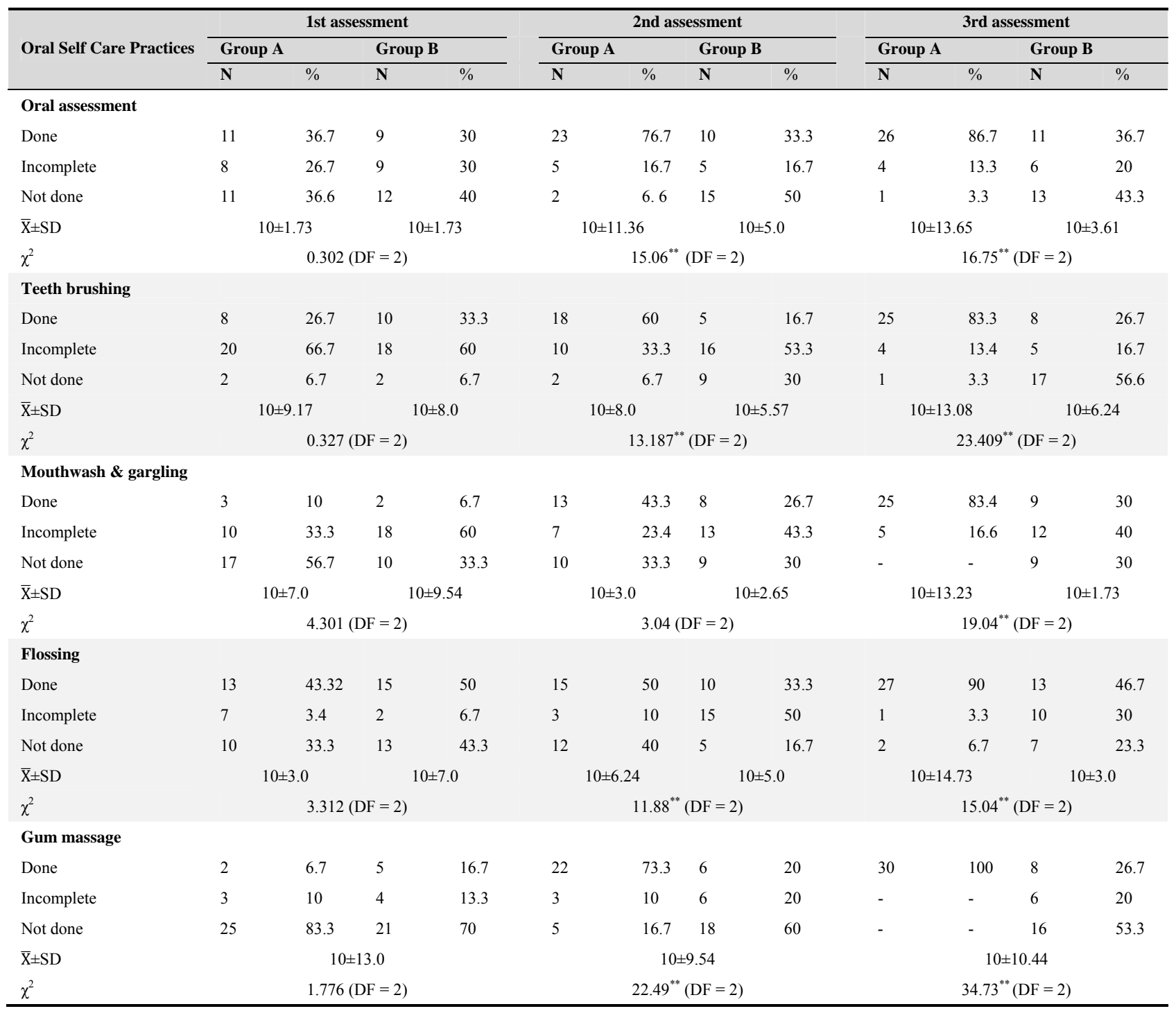

${ }^{*} p \leq .05 ;{ }^{* *} p \leq 0.01 ;{ }^{* * *} p \leq .001 ; \mathrm{DF}=$ Degree of freedom

Herbal therapy is frequently included in oral health care and education, particularly with diabetics, due to multiple factors especially the perception that pharmaceutical medications are expensive, have many side effects, are overprescribed, can cause stomach irritation if swallowed and are often dangerous. Alternatively, herbal medicine is often perceived as being "natural" and therefore it is considered safe if it is used in oral health problems. Patient awareness of herbs and their potential benefits and risks will enable health professionals to provide a balanced and objective view regarding them. Nurses are a source for encouraging clients to have appropriate information to make an informed choice. ${ }^{[24,26-28]}$

The present study proves that oral health education with herbs such as green tea powder produced excellent effects on diabetic patients' knowledge regarding diabetic effects on oral health, benefits of green tea in oral health care, and furthermore, knowledge about oral health care activities. This supports the first hypothesis. Before the educational intervention, there was a serious lack of knowledge among both patients groups. But after, the study group showed apparent improvements in this awareness as opposed to the control group.

The association between diabetes and oral health should be known by diabetic patients. Many researchers reported that diabetes is a strong risk factor for periodontal disease, affecting disease susceptibility, progression and severity. Gingivitis, particularly, is a common oral health complaint when coupled with diabetics. This is due to an increase in salivary 
glucose levels, mouth bacteria, tooth decay, inflammatory response and decreased body immunity. Patient awareness and oral health education play a central role in disease prevention, management and maintenance. Consistent with the principles of patient enforcement, diabetic patients and health care professionals share the responsibility for maintaining comprehensive oral health education as an integral part of general health but this principle has not yet been fully realized. ${ }^{[8,13,29-31]}$

Table 5. Gingivitis inflammation severity for the study and control groups in the 1st, 2nd, and 3rd assessments, before and after the health educational intervention

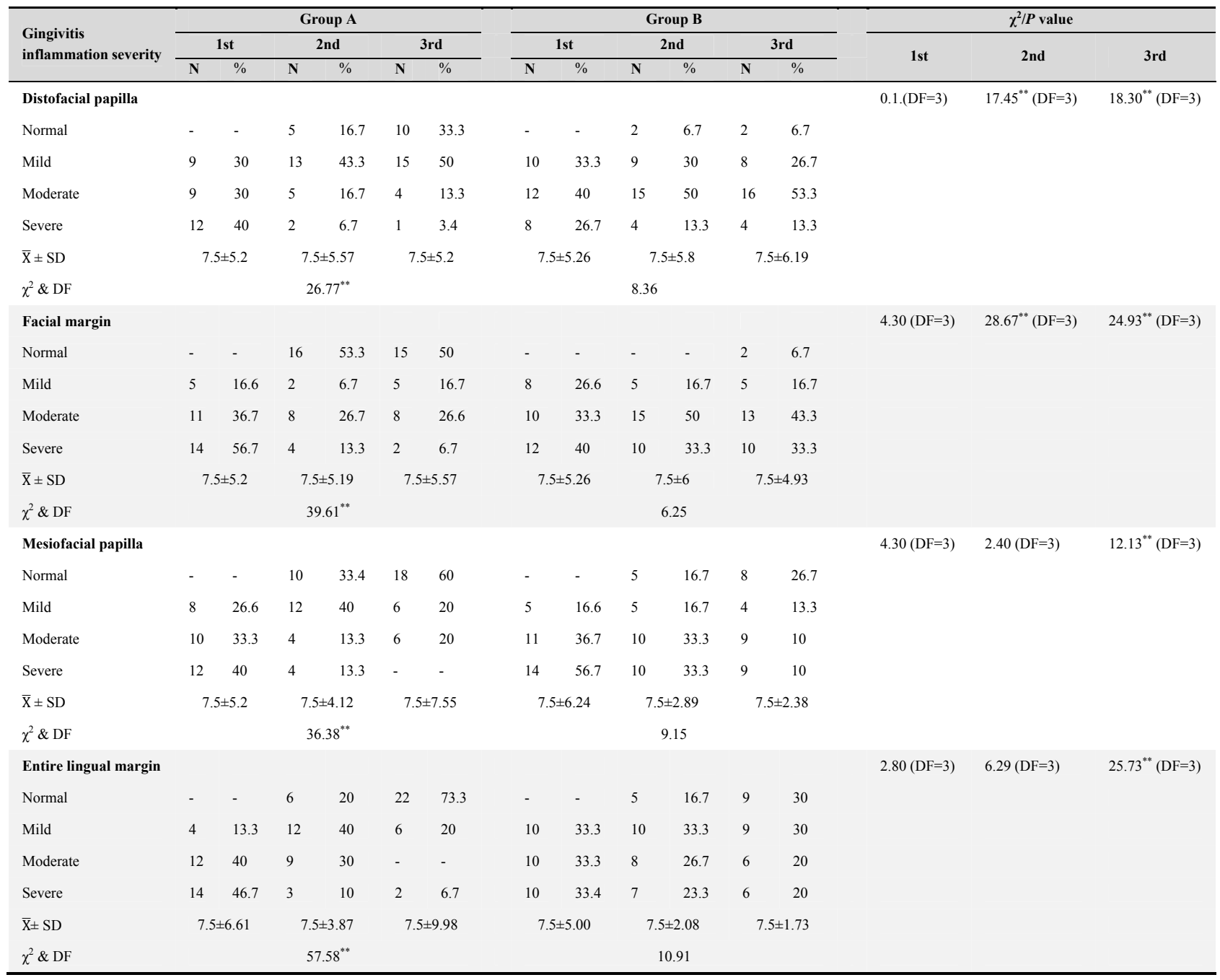

$* p \leq .05 ; * * p \leq .01 ; * * * p \leq .001 ; \mathrm{DF}=$ Degree of freedom

In the current study, the lack of patient knowledge before the educational intervention was expected which was supported by Mealey B. and Ocampo G. in 2007 who reported that many diabetic patients complained that oral health education is frequently neglected and patients rarely received any guidance about their oral health. So, today the health care system has an insistent need to plan and develop oral health education programs for these patients. ${ }^{[3]}$

After the educational intervention, the study group had more improved awareness about all oral health care activities such as the frequency of oral hygiene, teeth cleansing methods, Published by Sciedu Press frequency of dental visits, assessment of oral health, flossing the gingiva, massaging of gums and using green tea with gingivitis, than the control group. This result goes in line with Rankin S. in 2002 who clarified that patient literacy about their own health and illness care is considered a foundation in health management and a nurse should focus on helping them to acquire all skills or knowledge needed to deal with their health problems. ${ }^{[32]}$ Congruent with this view, Zhu L. in China in 2005 discussed that oral and dental awareness enhanced positive public attitudes toward oral health which increased the rate of seeking oral health services. ${ }^{[20]}$ 
Table 6. Gingivitis' manifestation in the study and control groups in 1st, 2nd, and 3rd assessments, before and after the health educational intervention

\begin{tabular}{|c|c|c|c|c|c|c|c|c|c|c|c|c|}
\hline \multirow{3}{*}{$\begin{array}{l}\text { Gingivitis' } \\
\text { Manifestation }\end{array}$} & \multicolumn{4}{|c|}{ 1st assessment } & \multicolumn{4}{|c|}{ 2nd assessment } & \multicolumn{4}{|c|}{ 3rd assessment } \\
\hline & \multicolumn{2}{|c|}{ Group A } & \multicolumn{2}{|c|}{ Group B } & \multicolumn{2}{|c|}{ Group A } & \multicolumn{2}{|c|}{ Group B } & \multicolumn{2}{|c|}{ Group A } & \multicolumn{2}{|c|}{ Group B } \\
\hline & $\mathbf{N}$ & $\%$ & $\mathbf{N}$ & $\%$ & $\mathbf{N}$ & $\%$ & $\mathbf{N}$ & $\%$ & $\mathbf{N}$ & $\%$ & $\mathbf{N}$ & $\%$ \\
\hline \multicolumn{13}{|l|}{ Gum bleeding } \\
\hline Present & 18 & 60 & 15 & 50 & 8 & 26.7 & 12 & 40 & - & - & 9 & 30 \\
\hline Absent & 12 & 40 & 15 & 50 & 22 & 73.3 & 18 & 60 & 30 & 100 & 21 & 70 \\
\hline$\chi^{2}$ & \multicolumn{4}{|c|}{0.606} & \multicolumn{4}{|c|}{1.200} & \multicolumn{4}{|c|}{$15.58^{* *}$} \\
\hline \multicolumn{13}{|c|}{ Redness of gingiva } \\
\hline Present & 30 & 100 & 27 & 90 & 12 & 40 & 22 & 73.3 & 5 & 16.7 & 18 & 60 \\
\hline Absent & - & - & 3 & 10 & 18 & 60 & 8 & 26.7 & 25 & 83.3 & 12 & 40 \\
\hline$\chi^{2}$ & \multicolumn{4}{|c|}{3.158} & \multicolumn{4}{|c|}{$6.789^{* *}$} & \multicolumn{4}{|c|}{$11.315^{* *}$} \\
\hline \multicolumn{13}{|c|}{ Swollen gingiva } \\
\hline Present & 20 & 66.7 & 18 & 60 & 13 & 43.3 & 10 & 33.3 & 2 & 6.7 & 8 & 26.7 \\
\hline Absent & 10 & 33.3 & 12 & 40 & 17 & 56.7 & 20 & 66.7 & 28 & 93.3 & 22 & 73.3 \\
\hline$\chi^{2}$ & \multicolumn{4}{|c|}{0.287} & \multicolumn{4}{|c|}{0.635} & & & & \\
\hline Tenderness gin & & & & & & & & & & & & \\
\hline Present & 15 & 50 & 12 & 40 & - & - & 9 & 30 & - & - & 7 & 23.3 \\
\hline Absent & 15 & 50 & 18 & 60 & 30 & 100 & 21 & 70 & 30 & 100 & 23 & 76.7 \\
\hline$\chi^{2}$ & & & 06 & & & & $8^{* *}$ & & & 37 & & \\
\hline Gingival sores & & & & & & & & & & & & \\
\hline Present & 12 & 40 & 15 & 50 & 8 & 26.7 & 12 & 40 & 1 & 3.3 & 12 & 40 \\
\hline Absent & 18 & 60 & 15 & 50 & 22 & 73.3 & 18 & 60 & 29 & 96.7 & 18 & 60 \\
\hline$\chi^{2}$ & & & 06 & & & & & & & & & \\
\hline Shinys of gingi & & & & & & & & & & & & \\
\hline Present & 9 & 30 & 12 & 40 & - & - & 10 & 33.3 & - & - & 9 & 30 \\
\hline Absent & 21 & 70 & 18 & 60 & 30 & 100 & 20 & 66.7 & 30 & 100 & 21 & 70 \\
\hline$\chi^{2}$ & & & 59 & & & & & & & 32 & & \\
\hline Halitosis & & & & & & & & & & & & \\
\hline Present & 13 & 43.3 & 15 & 50 & 2 & 6.7 & 12 & 40 & - & - & 12 & 40 \\
\hline Absent & 17 & 56.7 & 15 & 50 & 28 & 93.3 & 18 & 60 & 30 & 100 & 18 & 60 \\
\hline$\chi^{2}$ & & & 68 & & & & & & & & & \\
\hline Loose teeth & & & & & & & & & & & & \\
\hline Present & 15 & 50 & 20 & 66.7 & 12 & 40 & 20 & 66.7 & 10 & 33.3 & 17 & 56.7 \\
\hline Absent & 15 & 50 & 10 & 33.3 & 18 & 60 & 10 & 33.3 & 20 & 66.7 & 13 & 43.3 \\
\hline$\chi^{2}$ & & & 14 & & & & & & & & & \\
\hline Receding gums & & & & & & & & & & & & \\
\hline Present & 6 & 20 & 8 & 26.7 & 4 & 13.3 & 7 & 23.3 & 1 & 3.3 & 7 & 23.3 \\
\hline Absent & 24 & 80 & 22 & 73.3 & 26 & 86.7 & 23 & 76.7 & 29 & 96.7 & 23 & 76.7 \\
\hline$\chi^{2}$ & & & 02 & & & & & & & & & \\
\hline Pus in gingiva & & & & & & & & & & & & \\
\hline Present & 26 & 86.7 & 24 & 80 & 12 & 40 & 22 & 73.3 & - & - & 12 & 40 \\
\hline Absent & 4 & 13.3 & 6 & 20 & 18 & 60 & 8 & 26.7 & 30 & 100 & 18 & 60 \\
\hline$\chi^{2}$ & & & 48 & & & & & & & & & \\
\hline
\end{tabular}

${ }^{*} p \leq .05 ;{ }^{* * *} p \leq .01 ;{ }^{* * *} p \leq .001$ 
Contradictory to these points and during conversations with patients, they stated that, "Oral and dental care took minimal attention in Egypt," and their attention was directed only to the chronic illnesses. Furthermore, they justified that, "Oral and dental health is considered a minor complaint that can be resolved at home without health teaching. Only serious complaints such as severe pain or bleeding require the seeking of oral care." Similar to this view, Hmud R and Walsh in 2009 discussed that the fear of pain has been linked strongly to the development of dental anxiety and to avoidance of dental treatment. ${ }^{[5]}$ Even at optimal levels of oral illness many patients still consider themselves to be in good oral health. Moreover, among urban Saudi Arabians, Al-Otaibi M, and Månsson A, in 2004 concluded that oral hygiene routines were introduced relatively late in life and awareness of oral health was very low. ${ }^{[33]}$ Furthermore, in Southern China, Lin $\mathrm{H}$ et al., in 2001, reported that adults have poor oral health knowledge with negative attitudes toward oral health. Therefore, it is a time to correct and employ health education in this field. ${ }^{[34]}$

The existing results confirm that oral health education can have a positive effect on diabetic patient skills in performing oral health care as shown by the study group which fits with the second hypothesis. Fathy A, in 2006 recommended that the nurse should coordinate patient demonstrations in the nursing care plan and ask for administrative support to manage time and resources needed for this health teaching. ${ }^{[21]}$ In the same view, Kabil et al. in 2007 discussed that the chronic diseases which lead to oral health hazards must be managed through acquiring skills of self-care. Accordingly, patient activity is more important than nursing activity. ${ }^{[35]}$ In addition, Petersen et al. in 2005 mentioned that oral diseases are major public problems in the world and need optimal patient understanding to apply oral self care. ${ }^{[36]}$ Karikoski in 2003 clarified that teaching patients oral health practices are the major step for overcoming periodontal disease with diabetics and oral care specialists must put together an appropriate plan for proper oral health education. ${ }^{[37]}$

Concerning the application of green tea powder during oral health education sessions with the study group, it is granted that green tea is an effective herb for decreasing the severity of gingivitis and its manifestations, which matched the third hypothesis. Mouth care by green tea powder decreased the inflammation of gingivitis in Distofacial papilla, Facial margin, Mesiofacial papilla, and the Entire lingual margin inflammations and relieved its manifestations including redness, gingival tenderness, gingival shininess, halitosis, gingival pus, bleeding gums, gingival swelling, gingival sores, gum recession and loose teeth. This result was supported by King $\mathrm{B}$, in $2005^{[38]}$ who illustrated that green tea contains two very powerful polyphenolic compounds called catechins that have been shown to combat dental plaque, the main triggering factor for gingivitis. In addition, green tea powder has anticongestion and antimicrobial activity. Its polyphenols have demonstrated significant antioxidant, anticarcinogenic, thermogenic, probiotic, and antimicrobial properties in various human and animal trials. ${ }^{[17,39,40]}$

As well, it was revealed that rinsing and washing the oral cavity with green tea reduced dentin wear under erosive/abrasive conditions significantly better than rinsing with water. ${ }^{[41]}$ Furthermore, Magalha AC, et al., in 2009 illustrated that when chlorhexidine was applied in the form of a commercially available mouth rinse in comparison to application of a certain concentration of a green tea extract solution as a mouth rinse which aimed to simulate the catechin content normally found in green tea, the green tea was better than chlorhexidine. ${ }^{[30]}$ Moreover, green tea as chewable candy appears to reduce plaque accumulation and gingival inflammation. Its polyphenols reduce the cellular adhesiveness of bacteria associated with dental disease. ${ }^{[17,40,42]}$

Also, green tea acts as disinfectant for gingival tissue as proven by Chinese researchers; brushing the teeth with green tea powder which dissolved in warm water helps to block the growth of microbes which cause periodontal inflammation. When adding a few drops of green tea to a petri dish brimming with streptococcus mutants, the bacteria was completely restricted from multiplying after just five minutes. Therefore, green tea helps to decrease all gingival manifestation such as swelling, pain and congestion severity. ${ }^{[40,41,43]}$

Health teaching regarding green tea in mouth care verifies that it is an essential strategy to decrease oral health problems and thus strengthen the role of the nurse in complementary therapy. With implementation of complementary therapy education, nurses will re-establish a key role in this aspect, essentially in oral health care. Patient literacy about self-care management is considered a nuclear function of the professional nurse and a great responsibility of her job. Moreover, her/his role in health education will be activated which is generally neglected. Therefore, in the light of educational preparation for nurses, enough experiences in patient teaching in oral care will be an exceptional step for improving the nursing profession. ${ }^{[12,17,26,44]}$

\section{Conclusion}

Oral health education for diabetic patients with gingivitis is a successful approach for effective mouth self-care. Furthermore, oral care teaching about herbs is an essential scheme for nurses to improve their practice in delving in diverse fields such as dentistry and complementary therapy. 


\section{Recommendations and further studies}

Collaboration among the oral health team and other disciplines is encouraged especially in health education. The present study provided a view for further studies such as: (1) Investigation into the relation between awareness of diabetic patients towards herbal medicine and their compliance for this approach. (2) Collaboration for relevant research in oral health education and herbal medicines to test their safety and efficacy for managing other oral diseases.
(3) Conduct other research into using other types of herbs for oral health teaching in mouth problems such as gingivitis. (4) Replication of the current study with other clinical instruments and laboratory investigations as: $\mathrm{X}$ rays, $\mathrm{C}$ reactive protein, sedimentation rate, and local examinations as swab cultures or bleeding time or activity for gingival site. (5) Study using a larger sample, as well as a longer period of study time to confirm the effect of the health education with herbal management on minimizing oral health problem.

\section{REFERENCES}

[1] Karikoski A, Murtomaa H. Periodontal Treatment Needs in a Followup Study among Adults with Diabetes in Finland. Acta Odontol Scand. 2003; 6: 6-10.

[2] Boneta A, Stewart B, Proskin H. Comparative Investigation of the Efficacy of Triclosan/ Copolymer/ Sodium Fluoride and Stannous Fluoride/Sodium Hexametaphosphate/ Zinc Lactate Dentifrices for the Control of Established Supragingival Plaque and Gingivitis in a Six-Month Clinical Study. Clinical Dentistry Journal. 2010; 21(4): 117-123.

[3] Mealey B, Ocampo G. Diabetes Mellitus and Periodontal Disease. Journal compilation, Blackwell Munksgaard. 2007; 44: 127-153.

[4] Kandwal A, Batra M. Gingival Crevicular Blood as a Screening Tool for Diabetic Patient: a Randomized Clinical Trial. Annals of Dental Specialty. 2014; 2(1).

[5] Hmud R, Walsh LJ. Dental Anxiety: Causes, Complications and Management Approaches. Journal of Minimum Intervention in Dentistry. 2009; 2(1): 67-78.

[6] Matthews D. The Two-Way Relationship between Diabetes and Periodontal Disease. RCDSO DISPATCH Fall. 2005; 3: 1-12.

[7] Durante A, Romito R, Oliveira L, et al. Correlation Study of Plaque and Gingival Indexes of Mothers and Their Children. Journal OF Applied Oral Science. 2005; 13(3): 227-31. http://dx.doi.org /10.1590/S1678-77572005000300005

[8] Allen E, Ziada H, O'Halloran D, et al. Attitudes, Awareness and Oral Health-Related Quality of Life in Patients with Diabetes. Journal of Oral Rehabilitation. 2008; 35(3): 218-223. PMID:18254800. http://dx.doi.org/10.1111/j.1365-2842.2007.01760.x

[9] Kakar A, Newby E, Kakar K, et al. A Randomised Clinical Trial to Assess Maintenance of Gingival Health by a Novel Dentifrice Containing 0.1\%w/w o-cymen-5-ol and 0.6\%w/w zinc Chloride. International Dental Journal. 2011; 61(3): 13-20. PMID:21762150. http://dx.doi.org/10.1111/j.1875-595X.2011.00044.x

[10] Stankoa P, Hollab L. Bidirectional Association Between Diabetes Mellitus and Inflammatory Periodontal Disease. A review. 2014; 158(1): 35-38.

[11] Wordh I, Hallberg LR, Berggren U, et al. Oral Health Care-a Low Priority in Nursing. In-Depth Interviews with Nursing Staff. Scandinavian Journal of Caring Sciences. 2000; 14(2): 137-42. http: //dx.doi.org/10.1111/j.1471-6712.2000.tb00574.x

[12] Taha E. A Study for Developing Visual Educational Materials for Low Literate Adult Diabetics. MSN thesis, Faculty of Nursing, University of Alexandria. 1999; 13-6.

[13] Abd El Mohsen A. Barriers Encountered by Undergraduate Nursing Students While Providing Health Education for Patients. Unpublished Master Thesis. Faculty of Nursing, University of Alexandria. 2009; 34-12.
[14] Ministry of health. Nursing Management of Oral Hygiene. Singapore. 2004. Available from: http://www.moh.gov.sg/content/dam /moh_web/HPP/Nurses/cpg_nursing/2004/nursing_manag ement_of_oral_hygiene.pdf

[15] Foster S. Tea, Black/Green: (Camellia Sinensis). Thorne Research, Inc; 2002. 200-204 p.

[16] Lodhia P, Yaegaki K, Khakbaznejad A, et al. Effect of Green Tea on Volatile Sulfur Compounds in Mouth Air. J Nutr Sci Vitaminol. 2008; 54(1): 89-94. PMID:18388413. http://dx.doi.org/10.3177/j nsv. 54.89

[17] Neturi R, Srinivas R, Simha B, et al. Tea Effects of Green Tea on Streptococcus mutans Counts- A Randomised Control Trail. Journal of Clinical and Diagnostic Research. 2014; 8(11): ZC128-ZC130. PMID:25584303.

[18] Halder A, Raychowdhury R, Ghosh A, et al. Black Tea (Camellia sinensis) as a Chemopreventive Agent in Oral Precancerous Lesions. J Environ Pathol Toxicol Oncol Hirsch R. Diabetes and periodontitis. Australian Prescriber. 2004; 27(2): 36-38.

[19] Lambert J, Kwon S, Hong J, et al. Salivary Hydrogen Peroxide Produced by Holding or Chewing Green Tea in the Oral Cavity. Informa UK Ltd. 2007; 41(7): 850-853. http: //dx.doi .org/10.1080/1 0715760601091659

[20] Zhu L. Oral Health Knowledge, Attitudes and Behaviors of Adults of China. International Dental Journal. 2005; 55: 231-241. PMID:16167612. http://dx.doi.org/10.1111/j.1875-595X . 2005.tb00321.x

[21] Fathy A. Development of Patient Health Education Model to Guide Undergraduate Nursing Students. Unpublished MSN Thesis. Alexandria: University of Alexandria, Faculty of Nursing; 2006. 23-37 p.

[22] Butler A, Targett D, Bosma M. Maintenance of Gingival Health A measure Based on Clinical Indices. International Dental Journal. 2011; 61(3): 28-32. PMID:21762152. http://dx.doi.org/10. $1111 / \mathrm{j} .1875-595 \mathrm{X} .2011 .00046 . \mathrm{x}$

[23] Kantarci A, Cebeci I, Tuncer O, et al. Clinical Effects of Periodontal Therapy on the Severity of Cyclosporin A-Induced Gingival Hyperplasia. Journal of Periodontology. 1999; 70(6): 587-593. PMID:10397513. http://dx.doi.org/10.1902/jop.1999.70 .6 .587

[24] Brent A, Bauer MD. Herbal Therapy: What a Clinician Needs to Know to Counsel Patients Effectively. Nurse Education Today Journal. 2005; 80(6): 828 .

[25] Spardly B, Allender J. Community Health Nursing: Concepts and Practice. 4th ed. Philadelphia: Lippincott Co; 1996. 301-12 p.

[26] Cooper R, Morré J, Morré D. Medicinal Benefits of Green Tea: Part I. Review of Noncancer Health Benefits. Journal of Alternative and 
Complementary Medicine. 2005; 11(3): 521-528. PMID:15992239. http://dx.doi.org/10.1089/acm.2005.11.521

[27] Antigoni F, Dimitrios T. Nurses' Attitudes Towards Complementary Therapies. Health Science Journal. 2009; 3(3): 149-157.

[28] College of Nurses of Ontario Practice Guideline: Complementary Therapies. 2014. Available from: http://www.cno.org/Global /docs/prac/41021_CompTherapies.pdf

[29] Soskolne WA, Klinger A. The Relationship Between Periodontal Diseases and Diabetes: an Overview. Ann Periodontol. 2001; 6: 91-8. PMID:11887477. http://dx.doi.org/10.1902/annals. 2001 .6 .1 .91

[30] Magalha AC, WiegandA, Rios D, et al. Chlorhexidine and Green Tea Extract Reduce Dentin Erosion and Abrasion in situ. Journal of dentistry. 2009; 37: 94-998.

[31] Chalmers J, Spencer A, Carter K, et al. Caring for Oral Health in Australian Residential Care. Australian Institute of Health and Welfare. 2009; 48: 1-53.

[32] Rankin S, Stallings D. Patient Education: Principles and Practice. New York: Lippincott publisher; 2001. 290-400 p.

[33] Al-Otaibi M, Månsson A. Oral Hygiene Habits and Oral Health Awareness among Urban Saudi Arabians. Oral Health Prev Dent. 2004; 2(4): 389-96. PMID:16296258.

[34] Lin H, Wong M, Wang Z, et al. Oral Health Knowledge, Attitudes, and Practices of Chinese Adults. J Dent Res. 2001; 80(5): 1466-1470. PMID:11437221. http://dx.doi.org/10.1177/00220345010 800051601

[35] Kabil N, El Alfy M, Metwalli N. Evaluation of the Oral Health Situation of a Group of Egyptian Haemophilic Children And Their Re-Evaluation Following An Oral Hygiene and Diet Education Programme. The Official Journal of the World Federation of Hemophilia. 2007; 13(3): 287-292. PMID:17498078. http://dx.doi.org/10. $1111 / j .1365-2516.2007 .01440 . x$
[36] Petersen P, Bourgeois D, Ogawa H, et al. The Global Burden of Oral Diseases and Risks to Oral Health. Bull World Health Organization. 2005; 83(9).

[37] Karikoski A. Oral Self-care among Finnish Adults with Diabetes Mellitus - A focus on Periodontal Diseases. Published Thesis, Faculty of Medicine, University of Helsinki in the Main Auditorium of the Institute of Dentistry, Helsinki. 2003; 11-30.

[38] King B. Awaken Your Metabolism, Your Ultimate Guide to Abundant Energy. Health Venture Publication. Available from: http://www . abebooks.com/book-search/title/awaken-y our-metabolism-your-ultimate-guide-to-abundant-ene rgy/RetrievedinJanuary-2015

[39] Isogai E, Isogai H, Kimura K, et al. Effect of Japanese Green Tea Extract on Canine Periodontal Diseases. John Wiley \& Sons. 1995; 8: 57-61. http://dx.doi.org/10.3109/08910609509141383

[40] Löe H, Schiøtt R. The Effect of Mouth Rinses and Topical Application of Chlorhexidine on the Development of Dental Plaque and Gingivitis in Man. Journal of Periodontal Research. 2005; 24: 141144.

[41] Kato MT, Magalhaes AC, Rios D, et al. Protective EFfect of Green Tea on Dentin Erosion and Abrasion. Journal of Applied Oral Science. 2009; 17. PMID:20027426. http://dx.doi.org/10.1590 /S1678-77572009000600004

[42] Natural medicines, comprehensive database. Green tea. Therapeutic Research Faculty. 2007. Available from: http://faculty.ksu.ed u.sa/18856/Medicinal\%20Plants/GREEN\%20TEA.pdf

[43] Hsueh C. Gingivitis Treatment: Natural Remedies to Help Your Gums. 1993; 28: 4.

[44] Reisine S, Bailit H. Clinical Oral Health Status and Adult Perceptions of Oral Health. Nurse Education today Journal. 1980; 14(6): 597-605. 